Research Article

\title{
The Impact of R\&D Input on Technological Innovation: Evidence from South Asian and Southeast Asian Countries
}

\author{
Lei Lv, Yuchen Yin (D), and Yuanchang Wang $\mathbb{D}$ \\ School of Mathematics, Yunnan Normal University, Kunming 650500, China \\ Correspondence should be addressed to Yuanchang Wang; wangyuanchang@ynnu.edu.cn
}

Received 25 May 2020; Revised 15 July 2020; Accepted 13 September 2020; Published 7 December 2020

Academic Editor: Chi-Hua Chen

Copyright ( 92020 Lei Lv et al. This is an open access article distributed under the Creative Commons Attribution License, which permits unrestricted use, distribution, and reproduction in any medium, provided the original work is properly cited.

\begin{abstract}
In the era of the rapid development of knowledge economy and science, all countries have thought highly of technical innovation and greatly increased the R\&D input for it. However, the research on the impact of R\&D input on technical innovation lacks specialized, cross-country, and cross-time investigations, and especially, the research on small countries such as South Asia and Southeast Asia where technical innovation is relatively backward. So, does R\&D input in South Asia and Southeast Asia have an impact on technical innovation and to what extent? Let us analyze the panel data of 18 countries in South Asia and Southeast Asia from 2001 to 2018, use three methods of unit root test to test the stationarity of variables, adopt the Kao cointegration test to test a stable long-term relationship between the variables, and then, respectively, carry out the transnational regression analysis of the difference between patent applications, scientific journal articles, and the R\&D input with multiple models. Finally, the heteroscedasticity robust fixedeffect model is found to be the most suitable for this study after the comparative analysis of multiple models. Through the fixed-effect intercepts of each country in the heteroscedasticity robust fixed-effect models, South Asian and Southeast Asian countries are divided into three levels, and each level lists a set of equations. So, the following conclusions are drawn: both R\&D expenditure and manpower input in South Asia and Southeast Asia significantly promote technological innovation; the efficiency of both R\&D expenditure and manpower input promoting technological innovation in South Asia and Southeast Asia is low and needs to be improved. These conclusions provide references for policymakers in some countries where technological innovation is relatively backward, especially in Cambodia, Lao PDR, Myanmar, Timor-Leste, Bangladesh, Bhutan, Maldives, and Nepal.
\end{abstract}

\section{Introduction}

In this time of the high-speed development of information technology and knowledge economy, technology innovation has increasingly become an engine of social development, a decisive factor for all countries to enhance their international competitiveness and the vital motive of the continuous economic growth of a country or a region. Both developed and developing countries are increasingly aware of the importance of technological innovation in various aspects of economic and social development, even some small countries in South Asia and Southeast Asia where innovation is relatively backward are no exception. Improving the level of technology input has become the only way for countries to enhance their national comprehensive strength. Moreover, research and development (R\&D) is a major indicator to internationally measure the level of technology input, the innovation capacity, sustainable development potential, comprehensive technology strength, and competitiveness of a country or region in the world. Therefore, let us select the panel data of 18 countries in South Asia and Southeast Asia from 2001 to 2018 as the research sample to study the impact of R\&D input on technology innovation, which is not only conducive to promoting the improvement of the technological level of South Asian and Southeast Asian countries and enhancing the comprehensive strength of each country, but also has great theoretical value and practical significance.

Griliches developed the framework of knowledge production functions, and its framework could be simply expressed as $R \& D$ output $=F(R \& D$ input $)$. Meanwhile, the production function of C-D type was expressed as 
$R \& D$ output $=c(R \& D \text { input })^{\beta}$, where $c$ represented a constant term and $\beta$ denoted the output elasticity of $R \& D$ input [1]. Subsequently, Jaffe extended the framework of Griliches' knowledge production function, integrating the new economic knowledge pursued by enterprises into the production process, and the input variables included expenditure and manpower input for R\&D [2]. Romer, a representative of endogenous growth theory, proposed that knowledge accumulation and knowledge spillover effect of production capacity could make knowledge the main cause of technological innovation and economic growth [3]. After that, Jones revised Romer's knowledge production function and improved the theory and summarized Romer-Jones knowledge production function as $\widehat{A}=\delta L^{\lambda} A^{\phi}$. Among them, the term $\widehat{A}$ represented the knowledge production, $L$ denoted the R\&D manpower input, $A$ stood for the stock of knowledge, and $\delta$ was the synthesis of other external factors affecting knowledge production. The function showed that the production of new knowledge was the result of the joint action of the R\&D manpower input and the external factors of knowledge production and the knowledge stock. Obviously, R\&D expenditure investment belonged to the category of external influencing factor. According to this model, the scale of R\&D input was a decisive factor for the production of new knowledge when the knowledge stock and the R\&D manpower input were relatively constant [4].

In view of the relationship between $R \& D$ input and technology innovation, most scholars believed that $R \& D$ input had a positive impact on innovation, while a few scholars held the opposite attitude. Scheele, the first to make a quantitative study on the two, used the number of patents as an indicator to evaluate innovation, analyzed the data of 448 large American enterprises by establishing a linear model of R\&D input, sales, monopoly, and innovation, and empirically obtained that R\&D input had a positive impact on innovation performance [5]. Subsequently, Pakes and Griliches analyzed the data of 448 large American enterprises and found a significant positive relationship between patent applications and $R \& D$ input [6]. Crepon et al. believed that R\&D activities were divided into two processes, namely, input and output. Among them, R\&D expenditure was selected as input factor, and sales of patents and new products were selected as output factors to measure the relationship between input and output, and then the results showed that there was a positive relationship between the two [7]. Nasierowski and Arcelus obtained a positive correlation between $\mathrm{R} \& \mathrm{D}$ innovation efficiency and R\&D production capacity through the DEA method [8]. Pellegrino et al. classified R\&D input into two categories, specifically R\&D expenditures and personnel input, which were positively correlated with patent output [9]. Bogliacino and Pianta believed that R\&D input intensity had a significant role in boosting the innovation output of the industry and also played a positive role in promoting profit growth [10]. Baumann and Kritikos believed that the benefits from innovation in microenterprises were basically similar to those in large companies and the boost brought by R\&D input intensity to innovation in microenterprises was not much different from that in large companies [11]. Based on the analysis of Chinese regional innovation data in the past five years, Zhu et al. empirically tested that R\&D input generally had a significant positive impact on regional innovation performance under the premise of infrastructure control [12]. Moreover, Jefferson et al. and Le et al. also believed that R\&D input and innovation output were positively correlated $[13,14]$.

However, a few scholars had concluded that R\&D input did not always improve enterprise performance and uncertainty was an inherent characteristic of R\&D activities, which could inhibit the promotion of $\mathrm{R} \& \mathrm{D}$ activities to innovation output $[15,16]$. Compared with the high risk of returns, the probability of success of innovation activities was also relatively low, and the risk losses are likely to exceed returns. In the late 20th century, MOTOROLA invested in the iridium R\&D project, which ended in failure and cost the company $\$ 5$ billion [17]. This case became a typical representative of the failure of R\&D activities. Hitt et al. believed that the input was negatively correlated with enterprise performance because the risk of R\&D input was too high, so the enterprises with good business performance had little risk and were unwilling to take risks in R\&D activities [18]. Shi confirmed through research that $R \& D$ input would increase the risk and premium level of bonds, worsen the bond rating, damage the interests of creditors, and reduce the refinancing opportunities of the company [19]. In order to further verify the relationship between the two, Bin and Koellinger had obtained similar results by collecting data from different industries [20, 21]. For the manufacturing and information technology industry, Lu and Wang used the data of 99 listed companies in the manufacturing and information technology industry from 2005 to 2008 to empirically analyze that R\&D input harms corporate performance [22]. For the traditional manufacturing industry, $\mathrm{Qu}$ and $\mathrm{Lu}$ adopted the parametric stochastic frontier analysis method to study and found that the internal expenditures of $\mathrm{R} \& \mathrm{D}$ funds had a certain negative impact on the traditional manufacturing industry due to the unreasonable structure [23]. In a word, there are few studies on the negative inhibition effect.

To sum up, according to the theory of knowledge production function, most of the empirical research literature had illustrated the impact of R\&D input on technological innovation from various aspects, which had both positive promotion relationships and negative inhibition impact. But there are relatively fewer studies that have negative inhibitory effects. So there were two key points of disagreement among existing research conclusions. One was that scholars had different opinions on index selection, evaluation method, function mode, and performance size in empirical research. Secondly, in different periods, different industries, and different countries or regions, the impact of $\mathrm{R} \& \mathrm{D}$ input on technological innovation showed different characteristics. So, there was still a gap in existing studies, namely, the lack of cross-border and cross-time studies on the macro data at the national level, especially the studies of some small countries in South Asia and Southeast Asia. Furthermore, does $R \& D$ input in these small countries have an impact on technological innovation and to what extent? Let us analyze the panel data of 18 countries in South and Southeast Asia from 2001 to 2018, estimate multiple models and select the 
best model for the relationship between R\&D investment and technological innovation, so as to supplement the existing research, provide basic research for other countries to deepen technology cooperation with South and Southeast Asian countries, provide some enlightenment for the analysis of relevant technology policies, and provide a reference for policymakers in some countries where technological innovation is relatively backward, especially in Cambodia, Lao PDR, Myanmar, Timor-Leste, Bangladesh, Bhutan, Maldives, and Nepal.

\section{Model Design}

2.1. Variables and Data. Patent applications and scientific journal articles are regarded as dependent variables in this paper. Although the academic community has not reached a consensus on the quantitative indicators of technology innovation, most scholars measure the innovation outputs from the perspectives of patents and scientific journal articles, such as Chen et al. and Wang and Huang [24, 25]. Patents are particularly important because they are a kind of means for innovators to exchange knowledge and create economic value in the market [26]. So, Fritsoh and Franlce and Buesa et al. had emphasized that patents were a useful quantitative indicator of technology innovation [27, 28]. In fact, not all innovations are submitted as patents or other forms of technological achievements, and there are many other ways to transform knowledge into market value $[29,30]$. The number of scientific journal articles is one of the main indicators to measure the performance of knowledge creation and is also the main channel for research institutions and universities to provide local actors with technical outputs because it reflects the quality of technological activities in the region [31, 32].

$\mathrm{R} \& \mathrm{D}$ expenditure investment and $\mathrm{R} \& \mathrm{D}$ manpower input are taken as independent variables in this paper. R\&D expenditure investment is the primary factor influencing technological innovation and transformation, reflecting the R\&D scale of a region, as well as the basic innovation capacity and potential technological output capacity of a region $[33,34]$. So, Yoo had also emphasized that R\&D expenditure investment was a useful quantitative indicator of $R \& D$ input $[35,36]$. However, the use of a single variable to measure R\&D input is flawed, and it is easy to affect the empirical results due to the error of variable selection [37]. Moreover, the R\&D manpower input also represents the R\&D scale of the region and also reflects the technical innovation capacity and output capacity [38]. Higher technological innovation ability can also promote $R \& D$ expenditure investment to a certain extent [39]. Therefore, more existing studies have quantified the level of R\&D input through the R\&D expenditure and manpower input [40].

The control variables are selected from the following three aspects in this paper. Firstly, foreign direct investment partly reflects the economic openness level of a country [41, 42]. The level of economic openness has no direct impact on R\&D input, but it can increase the technological output of a region by improving the efficiency of R\&D input and independent innovation capabilities [43,44]. Secondly, government education expenditure provides the accumulation of knowledge for national scientific development and innovation and trains the talents needed $[45,46]$. Thirdly, regional innovation ability is affected by the regional economic development level to a certain extent, so the imbalance of each regional economic development level also determines the regional differences in technological innovation [47]. And GDP per capita is an important indicator of the macroeconomic performance of a country or region [48]. In short, it is necessary to regard the above three aspects as control variables in this paper. Table 1 shows the settings and descriptions of all the above variables.

The data in this paper are the panel data of all countries in South Asia and Southeast Asia from 2001 to 2018. The main data source is the relevant statistics released on Global Innovation Index 2018 and the official website of the World Bank. With the help of Stata 15.1 and EViews 8 analysis software, the estimation and analysis of multiple models including the mixed least square model, the random-effect model, the fixed-effect model, and the heteroscedasticity robust fixed-effect model are carried out. The missing data is obtained by trend extrapolation and multiple imputations and all variables adopt the winsorization method to conduct $1 \%$ double-tail reduction processing to eliminate the influence of extreme values on modeling analysis. As the cycle of technology innovation is generally long, the time is divided into six stages (2001-2003, 2004-2006, 2007-2009, 2010-2012, 2013-2015, and 2016-2018). Correspondingly, the time is $1-6$. The variables at each stage are averaged.

2.2. Theoretical Analysis and Basic Models. C-D knowledge production function is a vital theoretical model to study knowledge production, technological innovation, and its determinants [49]. In order to get the relationship between $\mathrm{R} \& \mathrm{D}$ input and technological innovation in South and Southeast Asian countries, we introduce R\&D expenditure investment and manpower input into a typical C-D knowledge production function:

$$
\begin{aligned}
& s j a_{i t}=A r e i_{i t}^{\alpha_{1}} r m i_{i t}^{\alpha_{2}}, \\
& p a t_{j t}=B r e i_{j t}^{\beta_{1}} r m i_{j t}^{\beta_{2}},
\end{aligned}
$$

where $\alpha_{1}, \beta_{1}$ and $\alpha_{2}, \beta_{2}$ are the output elasticity of R\&D expenditure investment and manpower input, respectively. In addition, $\mathrm{A}$ and $\mathrm{B}$ are both technological innovation efficiency, which are usually constant terms.

For reducing heteroscedasticity and increasing explanatory power of results, all variables are processed with log transformation to obtain the following model:

$$
\begin{aligned}
& \operatorname{lnsja}_{i t}=\ln A+\alpha_{1} \times \operatorname{lnrei} i_{i t}+\alpha_{2} \times \operatorname{lnrmi} i_{i t}+\omega_{i t}, \\
& \operatorname{lnpat}_{j t}=\ln B+\beta_{1} \times \operatorname{lnrei_{jt}}+\beta_{2} \times \operatorname{lnrmi} i_{j t}+\varphi_{j t},
\end{aligned}
$$

where lnsja means logarithm of the scientific journal articles, lnpat denotes logarithm of the patent applications, lnrei means logarithm of the R\&D expenditure investment, lnrmi denotes logarithm of the R\&D manpower input, and $\omega_{i t}$ and $\phi_{j t}$ are both random error terms. 
TABLE 1: Variable settings and descriptions.

\begin{tabular}{|c|c|c|}
\hline Variable name & $\begin{array}{l}\text { Variable } \\
\text { index }\end{array}$ & Description \\
\hline Scientific journal articles & sja & $\begin{array}{l}\text { The number of scientific and engineering articles published in the fields of physics, biology, } \\
\text { chemistry, mathematics, clinical medicine, biomedical research, engineering and technology, } \\
\text { Earth and space science, etc. }\end{array}$ \\
\hline Patent applications & pat & $\begin{array}{c}\text { The number of patent applications filed through the Patent Cooperation Treaty or with the } \\
\text { National Patent Office }\end{array}$ \\
\hline $\begin{array}{l}\text { R\&D expenditure } \\
\text { investment }\end{array}$ & rei & $\begin{array}{l}\text { The total domestic R\&D expenditure as a percentage of GDP, including capital and recurrent } \\
\text { expenditures of business, government, higher education, and private nonprofit institutions }\end{array}$ \\
\hline R\&D manpower input & rmi & $\begin{array}{l}\text { The number of scientific researchers engaged in research and improvement or development of } \\
\text { software for concepts, theories, models, technologies, instruments, and operating methods, } \\
\text { expressed as per million }\end{array}$ \\
\hline Foreign direct investment & fdi & The proportion of net inflow of foreign direct investment in GDP \\
\hline $\begin{array}{l}\text { Government education } \\
\text { expenditure }\end{array}$ & edu & The proportion of government education expenditure in GDP \\
\hline GDP per capita & gdp & GDP divided by mid-year population in each country \\
\hline
\end{tabular}

Based on the previous empirical literature and data availability, three control variables are added to equations (2) and (3), and then three econometric models are considered in this paper, namely, mixed least square models, fixed-effect models, and random-effect models. The specific models are as follows.

\subsubsection{Mixed Least Square Models.}

$$
\begin{aligned}
\ln s j a_{i t}= & \alpha_{0}+\alpha_{1} \times \operatorname{lnrei}_{i t}+\alpha_{2} \times \ln r m i_{i t}+\alpha_{3} \times \operatorname{lnfdi_{it}} \\
& +\alpha_{4} \times \operatorname{lnedu_{it}}+\alpha_{5} \times \operatorname{lngdp_{it}}+\lambda_{i t},
\end{aligned}
$$

$$
\begin{aligned}
& \operatorname{lnpat}_{j t}=\beta_{0}+\beta_{1} \times \operatorname{lnrei}_{j t}+\beta_{2} \times \ln r m i_{j t}+\beta_{3} \times \operatorname{lnfdi} i_{j t} \\
& +\beta_{4} \times \operatorname{lnedu_{jt}}+\beta_{5} \times \operatorname{lngd} p_{j t}+\eta_{j t} .
\end{aligned}
$$

\subsubsection{Fixed-Effect Models.}

$$
\begin{aligned}
& \ln s a_{i t}=\gamma_{i}+\alpha_{1} \times \ln r e i_{i t}+\alpha_{2} \times \ln r m i_{i t}+\alpha_{3} \times \operatorname{lnfdi_{it}} \\
& +\alpha_{4} \times \operatorname{lne} d u_{i t}+\alpha_{5} \times \operatorname{lngd} p_{i t}+\lambda_{i t} \text {, } \\
& \operatorname{lnpat}_{j t}=v_{j}+\beta_{1} \times \operatorname{lnrei}_{j t}+\beta_{2} \times \ln r m i_{j t}+\beta_{3} \times \ln f d i_{j t} \\
& +\beta_{4} \times \ln e d u_{j t}+\beta_{5} \times \operatorname{lngd} p_{j t}+\eta_{j t} .
\end{aligned}
$$

\subsubsection{Random-Effect Models.}

$$
\begin{aligned}
\ln s a_{i t}= & \gamma_{i}+\alpha_{1} \times \ln r e i_{i t}+\alpha_{2} \times \ln r m i_{i t}+\alpha_{3} \times \ln f d i_{i t} \\
& +\alpha_{4} \times \ln e d u_{i t}+\alpha_{5} \times \operatorname{lng} d p_{i t}+\lambda_{i t}+\varepsilon_{i t}, \\
\operatorname{lnpat}_{j t}= & \nu_{j}+\beta_{1} \times \ln r e i_{j t}+\beta_{2} \times \ln r m i_{j t}+\beta_{3} \times \ln f d i_{j t} \\
& +\beta_{4} \times \ln e d u_{j t}+\beta_{5} \times \operatorname{lng} d p_{j t}+\eta_{j t}+\mu_{j t},
\end{aligned}
$$

where lnfdi means logarithm of the foreign direct investment, lnedu denotes logarithm of the government education expenditure, lngdp represents logarithm of the GDP per capita, $i$ and $j$ both mean the countries, $t$ is the period, $\alpha$ and $\beta$ are both the regression coefficients, $\gamma_{i}, v_{j}(i, j=1, \ldots, 18)$ represent the unknown intercepts for each country (18 country-specific intercepts), $\quad \lambda_{i t}, \eta_{j t}(i, j=1, \ldots, 18$; $t=1, \ldots, 6)$ represent the between-entity error, and $\varepsilon_{i t}, \mu_{j t}(i, j=1, \ldots, 18 ; t=1, \ldots, 6)$ denote the within-entity error.

Finally, using the robust standard deviation of clustering to estimate the standard deviation, we get the heteroscedasticity robust fixed-effect model. The so-called cluster is a cluster of all the observations in each country at different times. The observations in the same cluster allow for correlation; the observed values from different clusters are not correlated.

\section{Model Testing and Discussion}

3.1. Unit Root Test and Cointegration Test. Considering that sometimes some economic data of time series themselves may not be directly related, often also show a common trend of change and appear the phenomenon of false regression, it is necessary to conduct the stationarity test on the panel data before the regression analysis, so as to avoid the problem of false regression and ensure the stationarity of the data. It is found that all of the eight variables show a time trend by drawing. Therefore, the model with the time trend is used to test the unit root of the eight variables, while the first difference variable has no time trend. The model without time trend is used to test the unit root. Let us use three methods to enhance the reliability of the research results, namely, the LLC test, the ADF test, and the PP test. The test results are shown in Table 2.

From the data in Table 2, it can be seen that in the case of the original value test, except that lnrei and lnrmi tests all passed the $1 \%$ significance level test, other variables failed; that is, there is a unit root. The $p$ values corresponding to all the statistics in the first-order difference sequence are all less than $1 \%$, indicating that all variables are stationary after the 
TABLE 2: Unit root test results.

\begin{tabular}{|c|c|c|c|c|c|c|}
\hline \multirow{2}{*}{ Variables } & \multicolumn{3}{|c|}{ Original value (time trend) } & \multicolumn{3}{|c|}{ First differences (no time trend) } \\
\hline & LLC test & ADF test & PP test & LLC test & ADF test & PP test \\
\hline lnsja & $-24.717^{* * *}$ & $51.671^{* *}$ & $83.433^{* * *}$ & $-3.046^{* * *}$ & $67.246^{* * *}$ & $69.978^{* * *}$ \\
\hline lnpat & $-8.818^{* * *}$ & $50.829^{*}$ & $95.098^{* * *}$ & $-4.851^{* * *}$ & $109.487^{* * *}$ & $111.286^{* * *}$ \\
\hline lnrei & $-42.601^{* * *}$ & $63.174^{* * *}$ & $98.324^{* * *}$ & $-8.793^{* * *}$ & $101.697^{* * *}$ & $108.817^{* * *}$ \\
\hline $\ln r m i$ & $-26.270^{* * *}$ & $71.882^{* * *}$ & $101.403^{* * *}$ & $-5.109^{* * *}$ & $76.861^{* * *}$ & $77.581^{* * *}$ \\
\hline $\operatorname{lnfdi}$ & $-14.805^{* * *}$ & 44.254 & $82.323^{* * *}$ & $-12.164^{* * *}$ & $130.025^{* * *}$ & $133.415^{* * *}$ \\
\hline $\operatorname{lnedu}$ & $-3.578^{* * *}$ & 16.831 & 23.617 & $-6.695^{* * *}$ & $77.284^{* * *}$ & $83.165^{* * *}$ \\
\hline $\operatorname{lngdp}$ & $-16.775^{* * *}$ & 39.923 & $71.300^{* * *}$ & $-4.198^{* * *}$ & $59.500^{* * *}$ & $61.025^{* * *}$ \\
\hline
\end{tabular}

${ }^{*} p<0.1 ;{ }^{* *} p<0.05 ;{ }^{* * *} p<0.01$.

first-order difference sequence; that is, all variables are firstorder integrals.

In order to further test whether there is a stable longterm relationship between the variables, we use the Kao test method based on the two-step test of Engle and Granger to test the cointegration. In the first stage of the Kao test, the regression equation is set as that each individual section has a different intercept term and the same trend term, and then all trend coefficients are set to 0 . In the second stage, based on the DF test and ADF test, the residual sequence obtained in the first stage is tested for stability. The test results are shown in Table 3. If the $p$ value is less than $1 \%$, it means that the original assumption of rejecting the Kao test "there is no cointegration relationship," that is, there is a stable longterm equilibrium relationship between variables. Therefore, the model established in this paper is correct and regression estimation can be conducted using panel data.

\subsection{Transnational Regression of R\&D Input and Scientific} Journal Articles. According to basic models (4), (6), and (8), we make the regression analysis on the panel data of South Asian and Southeast Asian countries. Table 4 lists the regression results of R\&D input and the number of scientific journal articles.

Since the growth cycle of the number of scientific journal articles is generally long, $R \& D$ input is related to long-term innovation, and the precise time model between R\&D input and scientific journal articles is not determined completely according to the annual data. Therefore, let us consider the influence of R\&D input on scientific journal articles in a suitable period of time and then set the time period as 3 years. The explanatory variable is the mean number of scientific journal articles in each period, and the other variables are also the mean values of each period. Moreover, the following system has four models, where model I is the mixed least square model, model II is the random-effect model, model III is the fixed-effect model, and model IV is the heteroscedasticity robust fixed-effect model. The weight of each country in the estimation process is the same but different standard error and time error correlations are allowed for each time period.

Compared with model I, model III is more suitable for this study. Model I does not consider the panel and time dimension when processing data. The main reason for extending the data to a panel data structure is to increase the
TABLE 3: Kao cointegration test results.

\begin{tabular}{lcc}
\hline & $t$-statistic & $p$ value \\
\hline ADF (lnsja) & -2.924390 & 0.0017 \\
ADF (lnpat) & -3.022997 & 0.0013 \\
\hline
\end{tabular}

$\mathrm{ADF}$ (lnsja) and ADF (lnpat), respectively, represent the cointegration test of lnsja and lnpat with explanatory variables and control variables.

amount of information in the sample. Although the main evidence comes from cross-sectional variations (between countries or regions), the time series dimension (within countries or regions) provides additional information. Within countries, this information is very useful for the explanatory variable in this paper because $R \& D$ input changes dramatically over time. In order to be scientific and rigorous, we first test model III with $F$-test to determine whether to use model I or model III before selecting the model, and then the Hausman test of model II is used to determine whether the following part should select model II or model III. The significance $p$ value of the $F$ test shows that $p<0.0001<0.05$, so it can be seen that model I is rejected and model III is selected for analysis. Moreover, the significance $p$ value of the Hausman test shows that $p=0.0194<0.05$, suggesting that model II is rejected and model III is selected for analysis. In summary, model III is selected after comprehensive consideration. Considering the problem of heteroscedasticity, the heteroscedasticity robust estimation is carried out for model III, and then model IV is obtained. The comparison between model III and model IV shows that the estimated coefficients of the two models are equal but the $p$ value of the coefficient of model IV after the heteroscedasticity robust treatment is generally larger than that of model III. And the number of * sign of lnrei is reduced from 3 to 2 ; that is, the explanatory variable becomes less explanatory to the explained variable. Moreover, the adjusted $R^{2}$ value increases from 0.788 to 0.823 , indicating that the overall fitting degree of the equation of model IV is higher. Therefore, model IV makes a more accurate estimate of R\&D input and scientific journal articles in this paper.

According to the regression coefficient and $p$ value $\left(\alpha_{1}=2.139, p<0.05\right)$ corresponding to lnrei, it means that lnsja increases by 2.139 units for each unit of lnrei but its changing degree is small, that is to say, R\&D input has a little impact on the number of scientific journal articles. Moreover, the ${ }^{* *}$ sign shows that lnrei is significantly related to 
TABLE 4: The regression results of R\&D input and scientific journal articles.

\begin{tabular}{lcccc}
\hline Variables & Model I & Model II & Model III & Model IV \\
\hline lnrei & $0.703^{* * *}(6.93)$ & $0.900^{* * *}(7.69)$ & $2.139^{* * *}(5.01)$ & $2.139^{* *}(2.39)$ \\
lnrmi & $0.491^{* * *}(3.71)$ & $0.907^{* * *}(5.54)$ & $1.098^{* * *}(5.26)$ & $1.098^{* * *}(3.03)$ \\
lnfdi & $-0.005(-0.16)$ & $-0.015(-0.69)$ & $0.057^{* *}(-2.28)$ & $-0.057^{* * *}(-3.21)$ \\
lnedu & $0.181(1.59)$ & $0.163(2.63)$ & $0.169^{* *}(2.60)$ & $0.169^{*}(1.69)$ \\
lngdp & $0.628^{* * *}(7.95)$ & $0.561(6.26)$ & $0.387^{* * *}(3.40)$ & $0.387^{*}(1.74)$ \\
cons (intercept) & $-12.74^{* * *}(-7.45)$ & $-18.74^{* * *}(-7.42)$ & $-39.09^{* * *}(-5.95)$ & $-39.09^{* *}(-2.74)$ \\
$R^{2}$ & 0.9418 & 0.8518 & 0.8317 & 0.8317 \\
Adjusted $R^{2}$ & 0.939 & 0.845 & 0.788 & 0.823 \\
$F$ values & $357.51^{* * *}$ & $117.23^{* * *}$ & $115.35^{* * *}$ & $84.00^{* * *}$ \\
\hline
\end{tabular}

The values in parentheses are the standard deviation of the coefficient estimation. ${ }^{*} p<0.1 ;{ }^{* *} p<0.05 ;{ }^{* * *} p<0.01$.

lnsja within the set confidence interval. Through lnrmi corresponding regression coefficients and the $p$ value $\left(\alpha_{2}=1.098, p<0.01\right)$, we can know that the coefficient is positive, which means that lnsja increases by 1.098 units for every 1 unit of lnrmi in the case of other conditions unchanged. But its changing degree is smaller than that of lnrei; that is, the impact of $R \& D$ manpower input on scientific journal articles is less than that of $R \& D$ expenditure investment. Moreover, the ${ }^{* * *}$ sign means that lnrmi within the set confidence interval is very significantly correlated with lnsja. By adding two explanatory variables into the model, it can be concluded that the effect of R\&D input on scientific journal articles cannot be considered from a single variable and that both $\mathrm{R} \& \mathrm{D}$ expenditure and manpower input can increase the number of scientific journal articles, so as to contribute to national technology innovation.

In the control variables, the coefficient margins of lnedu and lngdp are significantly positive, which can positively promote the publication of scientific journal articles. However, the coefficient of lnfdi is extremely negative, which will inhibit the production of scientific journal articles. With the increase of foreign investment in most south and southeast Asian countries except Singapore, a large amount of funds are used to purchase the readily available and relatively backward foreign technological achievements. As a result, local innovation subjects in many countries lack energy and funds to engage in innovation activities, which weakens the independent innovation ability of local innovation subjects and reduces the correlation between R\&D expenditure and technological innovation. As mentioned above, this is consistent with the negative correlation between foreign investment and the realization of technological innovation when foreign investment is taken as the control variable in this paper.

Through the fixed-effect intercept of each country in the model IV, we can know the specific equation of the relationship between R\&D input and scientific journal articles in each country from Table 5, such as the equation of Singapore, Philippines, and Myanmar:

$$
\begin{aligned}
\operatorname{lnsja}_{\text {Singapore }}= & 3.37946+2.139 \times \ln r e i_{t} \\
& +1.098 \times \ln r m i_{t}-0.057 \times \ln f d i_{t} \\
& +0.169 \times \operatorname{lned~}_{t}+0.387 \times \operatorname{lngdp} t+\lambda_{t},
\end{aligned}
$$

$$
\begin{aligned}
\ln s a_{\text {Philippines }}= & 0.13289+2.139 \times \ln r e i_{t} \\
& +1.098 \times \ln r m i_{t}-0.057 \times \ln f d i_{t} \\
& +0.169 \times \ln e d u_{t}+0.387 \times \operatorname{lngd} p_{t}+\lambda_{t}, \\
\ln j a_{\text {Myanmar }}= & -2.07867+2.139 \times \ln r e i_{t} \\
& +1.098 \times \ln r m i_{t}-0.057 \times \ln f d i_{t} \\
& +0.169 \times \operatorname{lnedu_{t}}+0.387 \times \operatorname{lngd} p_{t}+\lambda_{t},
\end{aligned}
$$

where $\lambda_{t}=-39.09$.

Table 5 shows the fixed-effect intercepts of each country in model IV, indicating that South and Southeast Asian countries have significant differences in scientific journal articles. From a horizontal perspective, India, Malaysia, Singapore, and Thailand have the largest number of scientific journal articles in South Asian and Southeast Asian countries, followed by Pakistan, Indonesia, Vietnam, Sri Lanka, Philippines, Bangladesh, and Brunei. The number of scientific journal articles in Cambodia, Lao PDR, Myanmar, Nepal, Bhutan, Timor-Leste, and Maldives is lagging behind, which further shows that these countries need to increase $\mathrm{R} \& \mathrm{D}$ expenditure investment and manpower input reasonably to improve the level of technological innovation.

\subsection{Transnational Regression of R\&D Input and Patent} Applications. According to the basic model (5), (7), and (9), we make the regression analysis on the panel data of South Asian and Southeast Asian countries. Table 6 lists the regression results of $\mathrm{R} \& \mathrm{D}$ input and patent application.

As the growth cycle of patent applications quantity is generally long, $\mathrm{R} \& \mathrm{D}$ input is related to long-term technology innovation, and the precise time model between $\mathrm{R} \& \mathrm{D}$ input and patent applications is not determined completely according to the annual data. Therefore, let us consider the effect of R\&D input on patent applications in a moderately long period of time and then set the time period as 3 years. The explanatory variable is the mean number of patent applications in each period and the other variables are also the mean values of each period. Moreover, the following system has five models, where model $\mathrm{V}$ is the mixed least square model, model VI is the random-effect model, model 
TABLE 5: The fixed-effect intercepts of each country in model IV.

\begin{tabular}{|c|c|c|c|c|c|}
\hline Country & Intercept & Country & Intercept & Country & Intercept \\
\hline India & 4.54196 & Vietnam & 0.90077 & Lao PDR & -1.94523 \\
\hline Malaysia & 4.33915 & Sri Lanka & 0.43807 & Myanmar & -2.07867 \\
\hline Singapore & 3.37946 & Philippines & 0.13289 & Nepal & -2.29419 \\
\hline Thailand & 3.20740 & Bangladesh & -0.35921 & Bhutan & -2.68533 \\
\hline Pakistan & 1.87514 & Brunei & -0.54005 & Timor-Leste & -4.39069 \\
\hline Indonesia & 1.84323 & Cambodia & -1.93539 & Maldives & -4.42933 \\
\hline
\end{tabular}

TABLE 6: The regression results of R\&D input and patent applications.

\begin{tabular}{lccccc}
\hline Variables & Model V & Model VI & Model VII & Model VIII & Model IX \\
\hline lnrei & $1.022^{* * *}(7.09)$ & $1.015^{* * *}(8.00)$ & $1.277^{* * *}(3.1)$ & $1.277^{* * *}(3.55)$ & $1.241^{* * *}(4.11)$ \\
lnrmi & $1.315^{* * *}(6.85)$ & $1.062^{* * *}(6.27)$ & $0.842^{* * *}(4.18)$ & $0.842^{* * *}(2.79)$ & $0.860^{* * *}(3.70)$ \\
lnfdi & $-0.061(-1.59)$ & $-0.037^{*}(-1.72)$ & $-0.031(-1.29)$ & $-0.031(-1.26)$ & - \\
lnedu & $0.318^{* *}(2.20)$ & $0.117^{*}(1.91)$ & $0.113^{*}(1.80)$ & $0.113^{*}(1.58)$ & $0.135^{*}(2.06)$ \\
lngdp & $0.292^{* *}(2.31)$ & $0.144(1.58)$ & $0.070(0.64)$ & $0.070(0.44)$ & $-23.34^{* * *}(-4.85)$ \\
cons(intercept) & $-25.17^{* * *}(-8.86)$ & $-21.81^{* * *}(-8.17)$ & $-23.90^{* * *}(-3.77)$ & $-23.90^{* * *}(-3.66)$ & -23.6148 \\
$R^{2}$ & 0.9253 & 0.7368 & 0.6148 & 0.6031 & 0.596 \\
Adjusted $R^{2}$ & 0.922 & 0.724 & 0.515 & 0.596 & $16.25^{* * *}$ \\
$F$ values & $119.08^{* * *}$ & $57.12^{* * *}$ & $27.13^{* * *}$ & $15.26^{* * *}$ \\
\hline
\end{tabular}

The values in parentheses are the standard deviation of the coefficient estimation. ${ }^{*} p<0.1 ;{ }^{* *} p<0.05 ;{ }^{* * *} p<0.01$.

VII is the fixed-effect model, and both model VIII and model IX are the heteroscedasticity robust fixed-effect models. The weight of each country in the estimation process is the same but different standard error and time error correlations are allowed for each time period.

As mentioned above, for the sake of scientificity and rigor, the $F$ test of model VII is conducted first before selecting the model, and then the Hausman test of model VI is conducted to determine whether the following model should be model $\mathrm{V}$, model VI, or model VII. Therefore, the significance $p$ value of the $F$ test shows that $p<0.0001<0.05$, so it can be seen that model VII is selected for analysis. Moreover, the significance $p$ value of the Hausman test shows that $p=0.0207<0.05$, suggesting that model VII is also selected for analysis. In a word, model VII is selected after comprehensive consideration. Compared with model V and model VI in this paper, model VII is the most suitable for this study. Considering the problem of heteroscedasticity, the heteroscedasticity robust estimation is carried out for model VII and model VIII is obtained. The comparison between model VII and model VIII shows that the coefficient values estimated by the two models are equal but the $p$ value of the coefficient of model VIII after the heteroscedasticity robust treatment is larger than that of model VII. Moreover, the adjusted $R^{2}$ value of the two models increases from 0.515 to 0.596 , indicating that the overall fitting degree of the equation of model VIII is higher. Therefore, model VIII makes a more accurate estimate of $\mathrm{R} \& \mathrm{D}$ input and patent applications in this paper.

Because lnfdi and lngdp of the control variables in model VIII have no significant effect on patent applications $(p>0.1)$, we get model IX after eliminating these two variables. And model IX is still the heteroscedasticity robust fixed-effect model. According to the regression coefficient and $p$ value $\left(\beta_{1}=1.241, p<0.01\right)$ corresponding to lnrei, it means that lnpat increases by 1.241 units for each unit of lnrei but its changing degree is small; that is to say, $\mathrm{R} \& \mathrm{D}$ input has little impact on patent applications quantity. Moreover, the ${ }^{* * *}$ sign shows that lnrei is very significantly related to lnpat within the set confidence interval. Through lnrmi corresponding regression coefficients and the $p$ value $\left(\beta_{2}=0.86\right.$, $p<0.01$ ), we can know that the coefficient is positive, which means that lnpat increases by 0.86 units for each unit of lnrmi in the case of other conditions unchanged. But its changing degree is smaller than that of lnrei; that is, the impact of R\&D manpower input on patent application quantity is less than that of $\mathrm{R} \& \mathrm{D}$ expenditure investment. Moreover, the ${ }^{* * *}$ sign means that lnrmi within the set confidence interval is also very significantly correlated with lnpat. By adding two explanatory variables into the model, it can be concluded that the impact of R\&D input on patent applications cannot be considered from a single variable and both $\mathrm{R} \& \mathrm{D}$ expenditure and manpower input can increase patent application quantity, so as to promote national innovation.

Through the fixed-effect intercept of each country in model IX, we can know the specific equation of the relationship between R\&D input and patent applications in each country from Table 7, such as the equation of Singapore, Philippines, and Myanmar:

$$
\begin{aligned}
\operatorname{lnpat}_{\text {Singapore }}= & 1.65928+1.241 \times{\ln r e i_{t}} \\
& +0.86 \times \ln r m i_{t}+0.135 \times \ln e d u_{t}-\eta_{t}, \\
\operatorname{lnpat}_{\text {Philippines }}= & 0.7860+1.241 \times \ln r e i_{t} \\
& +0.86 \times \ln r m i_{t}+0.135 \times \ln e d u_{t}-\eta_{t}, \\
\operatorname{lnpat}_{\text {Myanmar }}= & -3.1008+1.241 \times \ln r e i_{t} \\
& +0.86 \times \ln r m i_{t}+0.135 \times \ln e d u_{t}-\eta_{t},
\end{aligned}
$$

where $\eta_{t}=-23.34$. 
TABLE 7: The fixed-effect intercepts of each country in model IX.

\begin{tabular}{|c|c|c|c|c|c|}
\hline Country & Intercept & Country & Intercept & Country & Intercept \\
\hline Singapore & 1.65928 & Philippines & 0.78600 & Bhutan & -0.75375 \\
\hline India & 1.50356 & Brunei & 0.39971 & Maldives & -0.77819 \\
\hline Malaysia & 1.32618 & Sri Lanka & 0.16256 & Bangladesh & -0.85570 \\
\hline Indonesia & 1.20668 & Pakistan & -0.05891 & Cambodia & -1.15125 \\
\hline Thailand & 1.14805 & Nepal & -0.20206 & Lao PDR & -1.94089 \\
\hline Vietnam & 1.06440 & Timor-Leste & -0.41490 & Myanmar & -3.10078 \\
\hline
\end{tabular}

Table 7 shows the fixed-effect intercepts of each country in model IX, indicating that South and Southeast Asian countries have significant differences in patent applications. From a horizontal perspective, Singapore, India, Malaysia, Indonesia, and Thailand have the largest number of scientific journal articles in South Asian and Southeast Asian countries, followed by Vietnam, Philippines, Brunei, Sri Lanka, Pakistan, and Nepal. The number of scientific journal articles in Timor-Leste, Bhutan, Maldives, Bangladesh, Cambodia, Lao PDR, and Myanmar is lagging behind, which further shows that these countries need to increase R\&D expenditure investment and manpower input reasonably to improve the level of technological innovation.

\section{Model Result Analysis}

4.1. R\&D Input in South Asia and Southeast Asia Significantly Promotes Technological Innovation. Based on the regression analysis above, we find that both R\&D expenditure and manpower input in 18 countries are significantly positively correlated with the number of scientific journal articles and patent applications, so R\&D input significantly promotes technology innovation. The reasons may be as follows. Firstly, with the rapid development of science in South and Southeast Asia, the complexity and uncertainty of technology innovation increase, and the difficulty of advancing the development of frontier science increases. In this context, R\&D input in various countries can reduce the $\mathrm{R} \& \mathrm{D}$ cost and risk and promote the motivation of innovation for some R\&D institutions, especially in Cambodia, Lao PDR, Myanmar, Timor-Leste, Bangladesh, Bhutan, Maldives, and Nepal. Secondly, R\&D expenditure investment provides more financial support for the innovation output of South Asian and Southeast Asian countries. And it can attract more funds into the field of scientific research and expand the scale of scientific research expenditures, either directly by promoting enterprises to increase their own investment in technology, or indirectly by guiding financial institutions to make loans, especially in Singapore, India, Malaysia, Indonesia, and Thailand. These methods promote technology introduction and equipment upgrading, providing more favorable material conditions for R\&D activities. Thirdly, from the perspective of the long-term development needs of enterprises and related institutions, they need to increase the R\&D manpower input. And R\&D manpower input also provides sufficient manpower support for the innovation output of South Asian and Southeast Asian countries to ensure the smooth development of $R \& D$ activities and encourages researchers to improve their own strength in the hope of publishing more high-quality scientific articles and patents.

4.2. Efficiency of RङD Input Promoting Technology Innovation Is Low and Needs to Be Improved. The regression analysis above indicates that the positive effect of R\&D expenditure and manpower input on the number of scientific journal articles and patent applications is both a little weak within the established confidence interval, among which the positive impact of $\mathrm{R} \& \mathrm{D}$ manpower input is generally weaker than that of expenditure investment. So, we think that the effect of R\&D expenditure and manpower input on promoting innovation is not obvious and the using efficiency of R\&D input is low. In particular, the using efficiency of the R\&D manpower input in South Asia and Southeast Asia has more needs to be improved.

The reasons may be as follows. (a) The unreasonable R\&D expenditure structure: In the high-speed stage of economic development, many countries in South Asia and Southeast Asia prefer to invest in applied research and enterprise product development with strong competitiveness and higher returns, so that they cannot guarantee sufficient investment in basic research. It will lead to the brain drain, the lack of enthusiasm for innovation, and the difficulty in national innovation. (b) The inappropriate R\&D expenditure investment scale: At present, most of the national innovation systems of many countries in South Asia and Southeast Asia are still in the initial stage and the achievements of technological innovation are highly sensitive to the scale of the R\&D expenditure investment. So, the scale of the R\&D expenditure investment is not large enough, which will limit the process of innovation to some extent. This is especially true in countries where technological innovation is more backward, such as in Cambodia, Lao PDR, Myanmar, Timor-Leste, Bangladesh, Bhutan, Maldives, Nepal, and so on. (c) The long-term and posteconomic problems of the R\&D manpower input: On the one side, the $R \& D$ manpower input needs the transformation of knowledge and the time to carry out the activities of technological innovation, which makes the enterprises and institutions that pay attention to the current benefits less willing to invest human capital. On the other side, due to the ownership of human capital and the mobility of human resources, enterprises and social institutions are not willing to invest a lot of manpower. (d) The "quality" and "quantity" problems of the R\&D manpower input: Nowadays, the evaluation index of scientific researchers in South Asia and 
Southeast Asia is more focused on academic achievements, which brings about the lack of motivation for scientific researchers to industrialize and market their achievements. Universities and research institutes have a weak connection with the industry and their research achievements are out of step with the market demand. Although there are more and more technological personnel in South Asia and Southeast Asia, there is still a shortage of high-level innovative talents who can truly make technological breakthroughs.

\subsection{South Asian and Southeast Asian Countries Are Divided} into Three Levels according to the Fixed-Effect Intercepts of Each Country. Comprehensively considering the fixed-effect intercepts of each country in the heteroscedasticity robust fixed-effect models of scientific journal articles and patent applications, South Asian and Southeast Asian countries can be roughly divided into three levels in terms of technological innovation. Countries with higher technological innovation levels are Singapore, India, Malaysia, and Thailand; the countries with a medium level of technological innovation are Indonesia, Vietnam, Philippines, Brunei, Sri Lanka, and Pakistan; and the countries with a low level of technological innovation are Cambodia, Lao PDR, Myanmar, Timor-Leste, Bangladesh, Bhutan, Maldives, and Nepal. Through the equations (10) and (13), the equation of the relationship between R\&D investment and technological innovation in Singapore is obtained, which provides some inspiration and helps in the optimization of R\&D input in developed countries. Through the equations (11) and (14), the equation of the relationship between $\mathrm{R} \& \mathrm{D}$ input and technological innovation in Philippines is obtained, which provides a reference for developing countries to formulate technology policies. Through the equations (12) and (15), the equation of the relationship between $\mathrm{R} \& \mathrm{D}$ input and technological innovation in Myanmar is obtained, which can find some reasons for the relatively backward countries in technological innovation and bring some new inspiration to these countries.

\section{Policy Proposals}

5.1. All Countries in South Asia and Southeast Asia Should Continue to Increase the R\&D Expenditure and Manpower Input to Promote Technology Innovation. On the macrolevel, on the one side, all countries in South Asia and Southeast Asia should continue to increase manpower input in innovation and scientific research activities. On the other side, it is necessary to increase the input intensity in the $R \& D$ expenditure and actively guide enterprises and the society to increase it, which can enhance the national R\&D input level, ensure the continuous growth of national innovation output, and provide strong support for the national technological innovation. On the microlevel, enterprises need to increase the input in high-quality personnel for improving the innovation performance, and the most important thing is to increase the $R \& D$ expenditure investment. The $R \& D$ institutions should not increase manpower input on a large scale but should keep the R\&D expenditure investment moderately stable, stimulate the innovation enthusiasm of current direct manpower, and optimize the structure of manpower input. Colleges and universities should maintain a stable R\&D input, on this basis, appropriately increasing the intensity of manpower input. Therefore, increasing the $\mathrm{R} \& \mathrm{D}$ expenditure and manpower input is the basic means to improve the level of innovation.

\subsection{Countries Should Improve the Efficiency of the R\&D Input} to Promote Technology Innovation. Improving the efficiency of the R\&D input is the basic means to increase R\&D input to promote the effect of technology innovation. Based on the above analysis, in terms of the structure of expenditure investment, all countries need to make more scientific and reasonable decision-making basis in terms of how to rationally allocate expenditures in basic research, applied research, and enterprise product development. In terms of expenditure investment scale, as a key factor that directly affects the output of innovation, the R\&D expenditure investment should continue to increase its investment scale, expand the breadth and depth of technology and knowledge spillover, reasonably optimize the staged allocation of the R\&D expenditure, and especially increase the scale of investment in the transformation of technology achievements.

Aiming at the problem of R\&D manpower input, the R\&D manpower input in South Asia and Southeast Asia not only focuses on the increase in the number of the R\&D personnel to maintain a proper proportion relationship with the R\&D expenditure, but also pays attention to the improvement of R\&D personnel's knowledge reserve and professional skill. In particular, it is necessary to give full play to the technical expertise of core technical personnel in the transformation of technical achievements and the marketization of products, so as to promote the scale of national innovation output increasing returns. In particular, the technologically backward countries of South Asia and Southeast Asia should do these better, especially in Cambodia, Lao PDR, Myanmar, Timor-Leste, Bangladesh, Bhutan, Maldives, and Nepal.

In the high-speed stage of economic development, the $\mathrm{R} \& \mathrm{D}$ manpower in various countries is concentrated in the aspect of experimental development, which is more suitable for the current development situation. However, basic research is the cornerstone of the long-term and stable development of science and plays a supporting role in the overall development of R\&D activities. Gradually strengthening basic research is very significant for the longterm improvement of national innovation capacity and the development of technology, especially in Singapore, India, Malaysia, Indonesia, and Thailand. So, it is hoped that relevant departments of all countries in South Asia and Southeast Asia will take appropriate measures to provide enterprises and society with a more leading understanding of basic research and increase input in basic research.

\section{Data Availability}

The basic data of this article can be downloaded from the official website of the World Development Indicators of the 
World Bank. There is a public dataset that may be downloaded from https://databank.worldbank.org/home. Data supporting the results of this study can be obtained from the corresponding author upon request.

\section{Conflicts of Interest}

The authors declare that they have no conflicts of interest regarding the publication of this paper.

\section{Acknowledgments}

This research was sponsored by the National Natural Science Foundation of China (NSFC) (71163046) and the Natural Science Foundation of Yunnan Province (2018RD004).

\section{References}

[1] Z. Griliches, "Issues in assessing the contribution of research and development to productivity growth," The Bell Journal of Economics, vol. 10, no. 1, pp. 92-116, 1979.

[2] A. B. Jaffe, "Real affects of academic research," American Economics Review, vol. 79, no. 5, pp. 957-970, 1989.

[3] P. M. Romer, "Endogenous technological change," Journal of Political Economy, vol. 98, no. 5, pp. 71-102, 1990.

[4] C. I. Jones, "R\&D-based models of economic growth," Journal of Political Economy, vol. 103, no. 4, pp. 759-784, 1995.

[5] F. M. Scherer, "Firm size, market structure, opportunity and the output of patented inventious," American Economic Review, vol. 55, no. 5, pp. 1097-1126, 1956.

[6] A. Pake and Z. Griliches, "Patents and R\&D at the firm level: a first look report," Economics Letters, vol. 5, no. 4, pp. 377-381, 1980.

[7] B. Crepon, E. Duguet, J. Mairessec et al., "Research, innovation and productivity: an econometric analysis at the firm level," Economics of Innovation and New Technology, vol. 7, no. 2, pp. 115-158, 1998.

[8] W. Nasierowski and F. J. Arcelus, "On the efficiency of national innovation systems," Socio-Economic Planning Sciences, vol. 3, no. 37, pp. 215-234, 2003.

[9] G. Pellegrino, M. Piva, and M. Vivarelli, "Young firms and innovation: a microeconometric analysis," Structural Change and Economic Dynamics, vol. 23, no. 4, pp. 329-340, 2012.

[10] F. Bogliacino and M. Pianta, "Profits, R\&D, and innovation-a model and a test," Industrial and Corporate Change, vol. 22, no. 3, pp. 649-678, 2013.

[11] J. Baumann and A. S. Kritikos, "The link between R\&D, innovation and productivity: are micro firms different?" Research Policy, vol. 45, no. 6, pp. 1263-1274, 2016.

[12] H. L. Zhu, S. L. Zhao, and A. Abbas, "Relationship between $\mathrm{R} \& \mathrm{D}$ grants, R\&D investment, and innovation performance: The moderating effect of absorptive capacity," Journal of Public Affairs, vol. 20, no. 1, p. 1973, 2020.

[13] G. H. Jefferson, B. Huamao, X. J. Guan et al., "R\&D performance in Chinese industry," Economics of Innovation \& New Technology, vol. 15, no. 4-5, pp. 345-366, 2002.

[14] S. A. Le, B. Walters, and M. Kroll, "The moderating effects of external monitors on the relationship between R\&D spending and firm performance," Journal of Business Research, vol. 59, no. 2, pp. 278-287, 2006.

[15] D. Aboody and B. Lev, "Information asymmetry, R\&D, and insider gains," The Journal of Finance, vol. 55, no. 6, pp. 2747-2766, 2000.
[16] S. David Young, EVA and Value Based Management: A Practical Guide to Implementation, Mcgraw Hill Professional, New York, NY, USA, 2000.

[17] P. A. Abetti, "Critical success factors for radical technological innovation: a five case study," Creativity and Innovation Management, vol. 9, no. 4, pp. 208-221, 2000.

[18] M. A. Hit, R. D. Ireland, J. S. Harrison et al., "Effects of acquisitions on $\mathrm{R} \& \mathrm{D}$ inputs and outputs," Academy of Management Journal, vol. 34, no. 3, pp. 693-706, 1991.

[19] C. Shi, "On the trade-off between the future benefits and riskiness of R\&D: a bondholders' perspective," Journal of Accounting and Economics, vol. 35, no. 2, pp. 227-254, 2003.

[20] G. Bin, "Firm size, R\&D, and performance: an empirical analysis on software industry in China," Science Research Management, vol. 1, pp. 613-616, 2006.

[21] P. Koellinger, "The relationship between technology, innovation, and firm performance-empirical evidence from e-business in Europe," Research Policy, vol. 37, no. 8, pp. 1317-1328, 2008.

[22] Y. M. Lu and C. M. Wang, "Effect of R\&D investment on performance of Chinese listed companies-take manufacturing and IT industry as an example," Science and Technology Management Research, vol. 31, no. 5, pp. 122-127, 2011.

[23] X. Y. Qu, P. Lu, H. X. Wang et al., "Empirical analysis of the impact of $R \& D$ investment on the transformation and upgrading of China's traditional manufacturing industry," Statistics and Decision-Making, vol. 54, no. 5, pp. 120-123, 2020.

[24] C.-P. Chen, J.-L. Hu, C.-H. Yang et al., “An international comparison of R\&D efficiency of multiple innovative outputs: the role of the national innovation system," Innovation, vol. 13, no. 3, pp. 341-360, 2011.

[25] E. C. Wang and W. Huang, "Relative efficiency of R\&D activities: a cross-country study accounting for environmental factors in the DEA approach," Research Policy, vol. 36, no. 2, pp. 260-273, 2007.

[26] A. Ashish, F. Andrea, and G. Alfonso, "Markets for technology and their implications for corporate strategy," Industrial and Corporate Change, vol. 10, no. 2, pp. 419-451, 2001.

[27] M. Fritsch and G. Franke, "Innovation, regional knowledge spillovers and R\&D cooperation," Research Policy, vol. 33, no. 2, pp. 245-255, 2004.

[28] M. Buesa, J. Heijs, and T. Baumert, "The determinants of regional innovation in Europe: a combined factorial and regression knowledge production function approach," Research Policy, vol. 39, no. 6, pp. 722-735, 2010.

[29] Z. J. Acs, L. Anselin, and A. Varga, "Patents and innovation counts as measures of regional production of new knowledge," Research Policy, vol. 31, no. 7, pp. 1069-1085, 2002.

[30] W. Zhong, W. Yuan, S. X. Li, and Z. Huang, "The performance evaluation of regional R\&D investments in China: an application of DEA based on the first official China economic census data," Omega, vol. 39, no. 4, pp. 447-455, 2011.

[31] W. M. Cohen, R. R. Nelson, and J. P. Walsh, "Links and impacts: the influence of public research on industrial R\&D," Management Science, vol. 48, no. 1, pp. 1-23, 2002.

[32] M. G. Kocher, M. Luptacik, and M. Sutter, "Measuring productivity of research in economics: a cross-country study using DEA," Socio-Economic Planning Sciences, vol. 40, no. 4, pp. 314-332, 2006.

[33] A. Hashimoto and S. Haneda, "Measuring the change in R\&D efficiency of the Japanese pharmaceutical industry," Research Policy, vol. 37, no. 10, pp. 1829-1836, 2008. 
[34] V. Thomas, S. Sharma, and S. K. Jain, "Using patents and publications to assess R\&D efficiency in the states of the USA," World Patent Information, vol. 33, no. 1, pp. 4-10, 2011.

[35] U. Han, M. Asmild, and M. Kunc, "Regional R\&D efficiency in Korea from static and dynamic perspectives," Regional Studies, vol. 50, no. 7, pp. 1170-1184, 2016.

[36] S.-H. Yoo, "Public R\&D expenditure and private R\&D expenditure: a causality analysis," Applied Economics Letters, vol. 11, no. 11, pp. 711-714, 2004.

[37] H. Y. Lee and Y. T. Park, "An international comparison of R\&D efficiency: DEA approach," Asian Journal of Technology Innovation, vol. 13, no. 2, pp. 207-222, 2005.

[38] S. S. J. Thomas, "Inter-country R\&D efficiency analysis: an application of data envelopment analysis," Scientometrics, vol. 76, no. 3, p. 483, 2008.

[39] M. Docekalova and N. Bockova, "The use of data envelopment analysis to assess the R\&D Effectiveness of the Czech manufacturing industry," Verslas: Teorija Ir Praktika, vol. 14, no. 4, pp. 308-314, 2013.

[40] K. H. Chen and M. T. Kou, "Staged efficiency and its determinants of regional innovation systems: a two-step analytical procedure," Annals of Regional Science, vol. 52, no. 2, pp. 627-657, 2014.

[41] O. Ryoji, "Innovation, foreign direct investment and local content requirement," Osaka City University Economic Review, vol. 45, pp. 35-52, 2009.

[42] V. N. Balasubramanyam, D. Sapsford, and M. A. Salisu, "Foreign direct investment and growth," Social Science Electronic Publishing, vol. 70, no. 3, pp. 291-314, 1998.

[43] J. M. Arnold and B. S. Javorcik, "Gifted kids or pushy parents? foreign direct investment and plant productivity in Indonesia," Journal of International Economics, vol. 79, no. 1, pp. 42-53, 2010.

[44] K. Chen and J. Guan, "Measuring the efficiency of China's regional innovation systems: application of network data envelopment analysis (DEA)," Regional Studies, vol. 46, no. 3, pp. 355-377, 2012.

[45] A. M. P. Feldman, "R\&D spillovers and the geography of innovation and production," American Economic Review, vol. 86, no. 3, pp. 630-640, 1996.

[46] J. H. Grossman, P. P. Reid, and R. P. Morgan, "Contributions of academic research to industrial performance in five industry Sectors," Journal of Technology Transfer, vol. 26, no. 12, pp. 143-152, 2001.

[47] K. Kim, "An analysis of source of growth in East Asian economies and R\&D spillover effects," Korea \& the World Economy, vol. 1, no. 1, pp. 83-107, 2000.

[48] M. Jerzmanowsk, "Total factor productivity differences: appropriate technology vs. efficiency," European Economic Review, vol. 51, no. 8, pp. 2080-2110, 2007.

[49] T. Wei, "Impact of energy efficiency gains on output and energy use with Cobb-Douglas production function," Energy Policy, vol. 35, no. 4, pp. 2023-2030, 2007. 